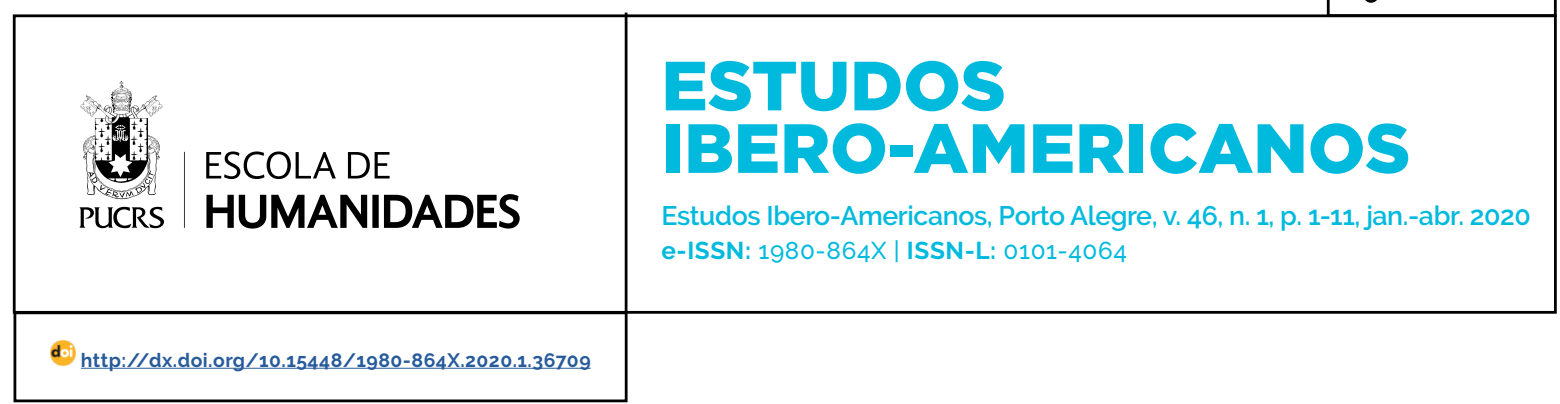

TRIBUNA

\title{
Notas para a compreensão do bolsonarismo'
}

\author{
Notes for understanding the Bolsonaro Government \\ Notas para entender el bolsonarismo
}

\section{Daniel Aarão Reis ${ }^{2}$ \\ orcid.org/0000-0003-0562-8940 \\ daniel.aaraoreis@gmail.com}

Recebido em: 23 dez. 2019.

Aprovado em: 5 jan. 2020.

Publicado em: 28 abr. 2020.
Resumo: O presente artigo tem como objetivo, em um primeiro momento, oferecer uma análise do fenômeno do bolsonarismo - conjunto de propostas e valores associados à ascensão política de Jair Bolsonaro ao governo da República brasileira. Em um segundo momento, haverá uma discussão preliminar sobre o caráter do governo Bolsonaro e das alianças que o apoiam e o sustentam.

Palavras-chave: Direitas. Autoritarismo. Governo Bolsonaro.

Abstract: This article aims, at first, to offer an analysis of the phenomenon of Bolsonaro government - a set of proposals and values associated with the political rise of Jair Bolsonaro to the government of the Republic. Secondly, there will be a preliminary discussion about the character of the Bolsonaro government and the alliances that support and sustain it.

Keywords: Right. Authoritarianism. Bolsonaro government.

Resumen: Este artículo tiene como objetivo, en primer lugar, ofrecer un análisis del fenómeno de el bolsonarismo: un conjunto de propuestas y valores asociados con el ascenso político de Jair Bolsonaro al gobierno de la República. En segundo lugar, habrá una discusión preliminar sobre el carácter del gobierno de Bolsonaro y las alianzas que lo apoyan y sostienen.

Palavras clave: Derecha. Autoritarismo. Gobierno de Bolsonaro

\section{Introdução: o contexto internacional da ascensão do bolsonarismo}

O bolsonarismo, em seus aspectos essenciais, não é um fenômeno apenas brasileiro. Insere-se em um contexto internacional de reação a mutações percebidas como ameaças mortais a tradições, valores e costumes.

Tais mutações constituem o cerne de um processo histórico que remonta os anos 1960 do século XX, quando se evidenciou a existência de uma grande revolução científico-tecnológica, que passou a subverter e a transformar, em profundidade, e em uma velocidade inaudita, a sociedade, a cultura, a política, a economia e os valores prevalecentes até então, sobretudo, mas não apenas, na área do capitalismo mais desenvolvido.

Também chamada de revolução digital ou informática, esse processo, nestes últimos cinquenta anos, tem mudado as condições de vida e de trabalho de quase toda a humanidade. 
Configuraram-se e se consolidaram como tendências ou aspectos principais dessa revolução, no campo econômico-social: a hegemonia do grande capital financeiro e suas propostas de desregulamentação dos mercados e privatização das atividades econômicas; a expansão e a consolidação dos chamados paraisos financeiros, onde se hospedam vultosos capitais, livres de fiscalização e tributação; o enfraquecimento da capacidade de decisão e de intervenção dos Estados Nacionais face ao livre fluxo de capitais, a instâncias internacionais e, no caso europeu, face às decisões da tecnocracia que rege importantes segmentos da vida econômica e social do continente; o surgimento de novos setores no campo da economia e da ciência (informática, biotecnologia, robótica, novos materiais, inteligência artificial etc.); o uso extensivo e intensivo dos dispositivos criados pela informática (internet, midias sociais, novos meios de comunicação etc.); o declínio demográfico da classe operária, principalmente na Europa e nos Estados Unidos, associado ao aparecimento de novas atividades profissionais e a extinção de diversas profissões tradicionais; a precarização e "informalização" das condições de trabalho de crescentes segmentos da população que vive de salários; a precarização e gradual degradação dos serviços públicos, mesmo ali onde tais serviços, em passado recente, tinham adquirido notável qualidade; a marginalização e a obsolescência de práticas e saberes tradicionais e consagrados; o surgimento das questões e lutas identitárias, dando vazão a demandas longamente reprimidas, mas, ao mesmo tempo, fragmentando o campo dos movimentos sociais populares e da crítica ao poder; e o aumento brutal das desigualdades sociais e regionais, mesmo em paises que registraram notável prosperidade, como a Índia e a China.

No campo político-institucional, podem-se destacar: a autonomização/"aristocratização" das instituições associadas à democracia representativa (políticas e juridicas), conduzindo a um progressivo descrédito dos partidos políticos e sindicatos, sobretudo entre a juventude e as classes populares; a curva ascendente do desinteresse, do absenteismo e de uma cultura política "cínica" baseada na desmoralização da mal chamada "classe política"; o uso pervasivo das midias sociais no contexto das lutas e embates políticos, seja para propagandear as próprias propostas, seja para desmoralizar as dos adversários (fake news); a irrupção de movimentos sociais autônomos em relação às instituições existentes, com demandas concretas, mas que, uma vez reprimidos, têm sido capazes de protagonizar revoltas sociais de grande amplitude. Em relação a esse último aspecto, cabe assinalar que se trata de um movimento universal, que remonta aos anos 1960, quando a ordem existente - capitalista e socialista - foi chacoalhada em seus fundamentos suscitando surpresa e perplexidade nas instituições politicas. ${ }^{3}$

Como resultado dessa revolução, construiuse um mundo de "areias movediças" ou uma "sociedade da insegurança"4, percebida como ameaçadora e desestabilizante por importantes setores sociais, desorientados ou/e amedrontados em virtude das mudanças radicais em curso. A irrupção de múltiplas ações terroristas, principalmente a partir de 2001, contribuiu, evidentemente, para o acirramento dos medos e para a aprovação de políticas securitárias que vêm pondo em risco as liberdades democráticas. ${ }^{5}$

Todas essas referências registradas acima tenderam a se acentuar e a se radicalizar a partir da crise econômica iniciada em 2008, porque, ao invés de jogar o peso da superação da crise sobre os ombros dos capitais financeiros, em particular sobre aqueles que faziam da especulação financeira sua atividade principal, tributandoos, reduzindo e regulamentando suas margens de ação, os diversos governos, ao contrário, fizeram um gigantesco esforço para recuperar a

\footnotetext{
3 A partir de então, e ao longo dos últimos cinquenta anos, cabe registrar que nenhum processo de lutas ou de mudanças, em larga escala, teve partidos e sindicatos como iniciadores ou como protagonistas de primeira grandeza. Cf. Daniel Aarão Reis, 2018

4 N. Fraser, 2007.

5 Cf. Timothy Garton Ash, 2009, em particular o cap. 3 (p. 161-212), onde se analisa a questão dos estereótipos construidos a respeito do fundamentalismo islâmico.
} 
economia às custas dos procedimentos habituais de "socialização das perdas", penalizando os assalariados e a qualidade dos serviços públicos.

Mesmo ali onde partidos social-democratas, liberal-sociais ou reformistas de diferentes tipos exerciam o poder, isoladamente ou em coligação, muito ou pouco, em muitos casos, quase nada, foi feito em beneficio das grandes massas dos que vivem de seu trabalho. Muito pouco, ou quase nada, foi feito em termos de uma crítica radical à hegemonia dos capitais financeiros e à sua prática de rapina em larga escala. Prevaleceu, ao contrário, uma política de gestão da crise, de apaziguamento e de capitulação face aos interesses destes capitais.

É verdade que certos Estados Nacionais, como a China, a Rússia e a Índia, criaram ou aperfeiçoaram políticas e mecanismos de controle, de regulamentação e de gestão centralizada da economia. Não por acaso, conseguiram manter as respectivas sociedades parcialmente a salvo dos efeitos mais deletérios da crise. No entanto, também eles não têm escapado às grandes tendências impostas pela revolução científicotecnológica e, não raro, para manter niveis de competitividade internacional, e apesar de indices positivos de crescimento, deixaram fluir, ou mostraram-se incapazes de deter, o processo geral de aumento das desigualdades sociais e regionais, reprimindo pela violência tentativas de crítica e de elaboração de alternativas.

É nesse quadro que têm surgido, às vezes com violência, movimentos sociais, motins urbanos e revoltas sociais em todos os continentes. Como referido acima, brotam por fora das instituições, procuram caminhos, registram aqui e ali o atendimento de reivindicações parciais, porém, quase sempre, esgotam-se sem conseguir impor mudanças significativas. Apesar disso, constituem, pela própria existência e dinâmica interna, o aspecto mais promissor do atual quadro, requerendo análises concretas, avaliações e balanços críticos, sem falar na necessidade de propostas alternativas para cada sociedade e a indispensável elaboração de uma articulação internacional.

Entretanto, ao lado desses movimentos de contestação, e também criticando as consequências suscitadas pela revolução digital, cresceu exponencialmente em anos recentes um outro tipo de processo: a reação nacionalista ${ }^{6}$.

A reação nacionalista ou nacionalismo de direita tem aparecido com grande força nos EUA (fenômeno Trump), na Europa Ocidental (Itália, França, Inglaterra), na Europa central (Hungria e Polônia), na Ásia (Filipinas e Índia), no mundo muçulmano (Irã e Egito) e na América Latina (Brasil, Chile, Colômbia). Trata-se de uma extrema-direita descomplexada, ativa e propositiva, de grande ativismo público, com frequentes incursões nas ruas, explorando as insuficiências e deficiências dos regimes democráticos, instrumentalizandoos quando convém, desfigurando-os "por dentro" e usando intensamente os mecanismos próprios da revolução digital.

Em cada lugar assume, evidentemente, aspectos próprios que precisam ser analisados concretamente. Em relação ao Brasil, voltaremos ao assunto na segunda parte deste artigo. Neste momento importa considerar seis aspectos centrais: o nacionalismo extremado de suas propostas; sua visada internacional, evidenciada em tentativas e práticas de articulação orgânica; seu viés visceralmente antidemocrático7; o conservadorismo social e religioso; a conquista, obtida através de uma ascensão fulminante, da condição de ator relevante e incontornável da luta política; e, finalmente, a capacidade de integrar e ser confluência de um conjunto de tendências de direita, cuja força se

\footnotetext{
6 Muitos autores ou/e políticos referem-se a esta tendência como "populismo de direita". Preferimos, por maior precisão, chamá-la de reação nacionalista ou nacionalismo de direita. Cf. para a defesa da primeira posição, Simon Torney (2018, p. 61-101), em particular o cap. 3, onde são analisadas as razões que têm desgastado os regimes democráticos. Voltaremos a considerar o assunto na segunda parte do artigo.

7 As ameaças ao regime democrático, veladas ou explícitas, integram o processo da reação nacionalista de extrema-direita e têm suscitado alarma e consternação. Cf., entre os lançamentos mais recentes: Adam Przeworski (2019), sem dúvida o estudo mais abrangente sobre a crise da democracia, com estudo de crises ocorridas no passado (século XX), diagnósticos sobre a crise atual e tentativa prospectiva. Seu objeto, entretanto, limita-se às sociedades capitalistas desenvolvidas. David Runciman (2018, p. 129-175), cap. 3 e Steven Levitsky e Daniel Ziblatt (2018, p. 76-98), cap. 4, são obras úteis, mas é preciso ressaltar que também trabalham com as sociedades europeias e estadunidense, não havendo referências especificas sobre a Ásia, África ou América Latina. Sobre a crise da democracia, de um ângulo jurídico-político, cf. Tom Ginsburg e Aziz Z. Huq (2018); David Landau (2013) e David Strauss (2018), todos também dedicados aos EUA.
} 
potencializa no quadro da reação nacionalista. De fato, tem sido possivel encontrar no seu interior tendências nacionalistas recentes; direitas tradicionais arcaizantes; nostálgicos do passado fascista/nazista e dos corporativos estatais autoritários ${ }^{8}$; direitas fundamentalistas religiosas; representantes de instituições repressivas (polícia e forças armadas) e direitas modernizantes liberais. Uma aliança instável, original, de novo tipo. As tentativas de reduzi-la a um de seus componentes tendem a perder de vistas as especificidades do novo animal politico que surgiu nesse momento histórico e que nada indica possa ser enfraquecido ou superado a curto e a médio prazos.

Caberia, ainda, mencionar aspectos especíicos da América Latina e que têm contribuido para a ascensão da reação nacionalista nesse continente. Em relação ao Brasil, a crise econômica de 2008 bateu forte em nossas paragens, embora muito subestimada na última fase do segundo governo Lula. Despencaram os preços das commodities que haviam sido a locomotiva da prosperidade latino-americana nos primeiros anos do novo século. Diminuíram, assim, as margens econômicas para políticas redistributivas. Por outro lado, os governos nacional-estatistas, emparedados por suas opções e políticas conciliatórias, não ousaram (não é sua tradição) recorrer à mobilização e à organização popular que fossem capazes de apoiar e sustentar políticas alternativas. Nada foi feito neste sentido. De sorte que, um pouco por toda a parte, as gentes desarmaram-se para compreender e enfrentar os fenômenos que estavam acontecendo ou viriam a acontecer. Prevaleceu o incentivo a esperar tudo do Estado, a olhar para cima, que os "cuidados" e a "salvação" viriam do alto, pacificamente. O reformismo "mole". A crise das políticas nacional-estatistas, que recentemente ganharam novo fôlego na Argentina e no México, devido a desastrosas gestões liberais, foi uma importante munição para a ascensão da reação nacionalista que efetua comparações entre o nacional-estatismo e o fenômeno do comunismo internacional que assombrou essa parte do mundo desde os anos 1920, acentuando-se a partir da vitória da revolução cubana, em 1959.

Em toda a parte, a extrema-direita tem levantado a cabeça. E continuará, no mínimo, por um bom tempo, com a cabeça bem levantada, intimidando e ameaçando.

O bolsonarismo é a face brasileira desse fenômeno.

Como compreender, nas condições brasileiras, seu crescimento fulminante?

\section{$1 \mathrm{~A}$ ascensão do bolsonarismo no Brasil}

Como tudo o que acontece na história, o bolsonarismo não caiu como um raio de um céu azul, embora muitos, até hoje, ainda o ressintam como tal.

Para compreender o fenômeno, proponho o entrelaçamento de três dimensões. Analisar as tradições autoritárias que marcam a história da sociedade brasileira. Compreender a grande conjuntura que se estende a partir da aprovação da Constituição de 1988 até o ano de 2018, quando se verificaram as eleições presidenciais. Finalmente, a campanha eleitoral ou a conjuntura política curta, que acrescentou importantes - e decisivos - ingredientes para entender a vitória de Jair Bolsonaro. Penso que só o agenciamento dessas três dimensões - a longa, a média e a curta durações - é que será capaz de oferecer subsídios para que se compreenda a vitória eleitoral da reação nacionalista de extremadireita em nosso país.

\subsection{As tradições autoritárias}

Em relação às tradições autoritárias, antes e durante muito tempo subestimadas, é notável como a atenção dos estudiosos têm se voltado para sua análise. Eu seria o último a lamentar o fato. Desde início deste século, em livros

\footnotetext{
8 A presença de núcleos nostálgicos do fascismo e do nazismo no interior da reação nacionalista de extrema-direita tem levado muitos a apresentar este fenômeno novo e específico como uma ressurgência do fascismo/nazismo dos anos 1930. Para a especificidade do nazi-fascismo, que dispõe de abundante bibliografia,cf. Emilio Gentile, 2005, sobretudo a II Parte (pp 169-375) e Robert Paxton, 2007, em particular os capítulos 7 e 8 (pp 283-361). Para uma sintese da especificidade do fascismo, segundo Paxton, cf. pp 358-361. Cf. ainda os estudos clássicos de Renzo Felice, 1977; e Zeev Sternhell, 1994. Para o corporativismo estatal, cf. Antonio Costa Pinto, 2014.
} 
e artigos, tenho enfatizado a importância de compreendermos como as duas ditaduras modernizantes que marcaram a história do País ao longo do século XX - o estado novo (1937-1945) ea ditadura civil-militar (1964-1979) - estabeleceram o que chamei de "relações complexas" com a sociedade brasileira. Ao contrário de um certo senso comum, não foram apenas estabelecidas "de cima para baixo", não subsistiram apenas em virtude da ação dos aparelhos repressivos (embora esses, evidentemente, tenham desempenhado importante papel), não foram apoiadas apenas pelas "elites" ou "classes" dominantes, porém, segundo as conjunturas, construiram relações de aceitação, de indiferença, de neutralidade ou de apoio ativo e ostensivo com numerosos segmentos sociais (empresariado, forças armadas, burocracia civil estatal, intelectuais, classes médias e segmentos populares). Em torno das duas ditaduras, em alguns momentos, foi possivel construir um consenso social significativo o que muito explica sua instauração pacifica, sua duração e os processos que levaram a sua superação. Importantes trabalhos historiográficos têm evidenciado a adequação dessa proposta interpretativa9. Sem embargo, muitos continuaram embalados pela anunciada "democracia consolidada" e pela interpretação de que as classes populares, salvo operações de "maquiagem" ou/e de "manipulação", permaneciam infensas à ditadura e a seus valores autoritários. Cairam agora das nuvens, o que é sempre melhor, como recordava Machado de Assis, do que cair do terceiro andar de um prédio.

Recente livro relacionou com minúcias as modalidades principais em que se apoiam as tradições autoritárias no Brasil ${ }^{10}$ : o racismo e as mal superadas relações escravistas; o mandonismo, produto das relações agrárias; o patrimonialismo; a corrupção; a desigualdade social; a violência; a intolerância; a discriminação de raça e gênero. Um passado que se recusa a passar, que continua dificultando progressos sociais e culturais. Fantasmas que permanecem assombrando, condicionando, apesar das mutações realizadas, a história da sociedade nas últimas décadas.

Trata-se de referências exatas e indispensáveis para compreender o presente, desde que não expulsem da análise opções políticas que foram adotadas e que contribuíram, em não pequena medida, para acentuá-las e torná-las vivas e operantes no presente momento.

$\mathrm{Na}$ consideração das tradições, porém, é necessário estabelecer mediações. Houve um momento, nos anos 1970, em que se tornou comum atribuir a onda de ditaduras na América Latina às "nossas raizes ibéricas", autoritárias, excludentes, intolerantes ${ }^{11}$. O que não impediu, nessa mesma década, que as sociedades/berços históricos desta civilização - Portugal e Espanha - empreendessem notáveis e exitosos processos de transição democrática. Terão sido então vencidas essas tradições? Uma resposta positiva à questão seria de uma pobreza franciscana. Ocorreu que foram redefinidas por ações e decisões que souberam lidar com elas. Como sempre recordava o escritor israelense, Amos $\mathrm{Oz}$, o passado nos foi entregue, não fomos entregues ao passado. Em outra formulação, também do mesmo escritor: o passado nos pertence, não pertencemos ao passado.

O que evidenciam esses exemplos? Que tradições, por mais fortes que sejam, não exaurem a análise, por mais robustas, historicamente, não podem e não devem expulsar dos radares as lutas politicas e sociais e as opções que as vertebram. Em suma, a história não pode anular ou excluir a politica, ou melhor, as tradições não podem expulsar a política da história.

De sorte que, sem ignorar ou minimizar as tradições autoritárias, cumpre integrar na análise referências da média duração (grande conjuntura entre 1988/2018) e da curta duração (campanha eleitoral de 2018)

\footnotetext{
9 Entre outros, mencionaria Daniel Aarão Reis, Rodrigo Patto Sá Motta e Marcelo Ridenti, (2014); Rodrigo Patto Sá Motta (2014); Denise Rollemberg (2008, 2010, 2010a); Lucia Grinberg (2009); Janaina Cordeiro (2015); Gustavo Ferreira (2015); Tatyana Maia (2012); Paulo Cesar Gomes (2019); Livia Magalhães (2014).

10 Lila Moritz Schwarcz (2019). E, também, Heloísa Murgel Starling (2019).

${ }_{11}$ Cf. Juan Lins e Alfred Stepan (1978) e Juan Linz (2000)
} 


\subsection{A média duração: a grande conjuntura 1988/2018}

Tem sido recentemente enfatizada a crise terminal da "Nova República", sobretudo depois da reeleição de Dilma Roussef para um segundo mandato, em 2014. Rompeu-se, então, o consenso quanto aos resultados eleitorais, fossem eles quais fossem, e se passou a atacar a presidente eleita de forma ostensiva, culminando na aprovação do impeachment da mesma, em 2016, um instrumento autoritário por excelência. ${ }^{12}$

Nas eleições de 2018, ao contrário das anteriores, os embates já não se deram entre tucanos vs. petistas, crescendo "por fora", de maneira fulminante, a candidatura de Jair Bolsonaro, cuja pregação, propostas e valores antagonizavam abertamente os valores e as propostas que conformavam a "Nova República". Face a esse quadro, muitos inclusive chegaram a constatar a "falência" do experimento político construído desde a aprovação da Constituição de 1988 e a propor a existência de uma nova "fase" da história política brasileira a partir da ascensão do bolsonarismo. ${ }^{13}$

Aceite-se ou não essa interpretação, o fato é que a análise do desdobramento da "Nova República", nestes trinta anos que medeiam entre a aprovação da Constituição de 1988 e as últimas eleições presidenciais (2018), nos oferece uma plataforma de observação, entre o curto (campanha eleitoral) e o longo prazo (tradições) que é importante para compreender certos fenômenos essenciais que ensejaram condições favoráveis à ascensão do bolsonarismo.

Vou direto ao ponto que me parece mais importante: o fato de que os partidos reformistas criados no contexto da Nova República, o PT, no início dos anos 1980, e o PSDB, em meio aos debates da Constituinte, em 1988, foram, gradativamente, perdendo suas referências inovadoras, sugados pelas dinâmicas tradicionais da "classe política", no que essa tinha - e tem - de mais conservador e repulsivo (corrupção, fisiologia, troca-troca de siglas, descompromisso com principios etc.). Vale acrescentar, igualmente, com a necessária ênfase, o pouco empenho que os dois referidos partidos tiveram no que se relaciona ao debate a respeito da ditadura civil-militar (1964-1979) e de seus legados, em particular os inscritos no corpo da Constituição de 1988. Debates a respeito desse passado, que ainda está presente, com certeza contribuiriam para a construção de uma consciência cidadã, afeita aos valores democráticos. ${ }^{14}$

Os partidos reformistas mereceram a confiança de uma grande maioria da sociedade e ganharam, sucessivamente, seis mandatos presidenciais (FHC, entre 1994-2002; Lula, entre 2002-2010; e Dilma, em 2010 e 2014). Realizaram políticas que correspondiam às demandas das maiorias (controle da inflação/FHC); políticas de distribuição de renda e inclusivas (aumentos reais do salário mínimo, política de cotas para ingresso nas universidades e serviços públicos, política tributária de incentivo à aquisição de bens de consumo etc.), realizadas nos governos de Lula e Dilma.

Entretanto, sobretudo a partir da crise de 2008 , no quadro do acirramento das contradições sociais que acompanham qualquer grande crise, esses dois partidos foram incapazes de retomar uma dinâmica inovadora que conferira a eles destaque no quadro partidário nacional. Ao contrário: enredaram-se, confundiram-se, consolidaram suas alianças com as "forças do atraso", não souberam lidar com as demandas sociais crescentes por serviços públicos de qualidade; por políticas claras de combate à corrupção; por políticas construtivas e positivas quanto à questão da segurança que se tornaria um problema central a atormentar a vida das pessoas comuns, principalmente das camadas populares. A inclusão - direta ou indireta - de suas principais lideranças em grandes escândalos de corrupção contribuíram não só para desmoralizá-las, e a seus partidos, mas também para abalar a credibilidade

\footnotetext{
12 Na interpretação dos petistas e dos lulistas e de outros agrupamentos de esquerda, tratou-se de um "golpe de estado" parlamentar camuflado, progressivo, efetuado "por dentro" das próprias instituições democráticas. Curioso é que estas forças, desde 1988, recorreram diversas vezes ao impeachment, sem que o recurso a este mecanismo essencialmente autoritário lhes parecesse questionável.

13 Cf. Angela Alonso (2019) e Esther Solano, idem.

14 Cf. Daniel Aarão Reis (2019a).
} 
do conjunto do sistema político, cada vez mais visto como um cadáver apodrecendo à luz do dia.

Neste quadro, os grandes movimentos sociais ocorridos em 2013 não foram convenientemente analisados e interpretados. Constatou-se o imenso desgaste que afetava partidos e lideranças, mas não houve a capacidade - ou a vontade - de reverter os rumos, como se PSDB e PT tivessem se transformado apenas em gestores de um sistema que eles haviam prometido reformar.

Não apenas perderam a dinâmica reformista, mas "se lambuzaram ${ }^{15}$ " alegremente com prebendas, pecúnias e propinas. A "aristocratização" das instituições politicas e juridicas, que já vinha se consolidando há décadas, ganhou intensidade sob os governos tucanos e petistas sem que estes, em nenhum momento, assumissem uma atitude critica. As direitas aproveitaram-se para criminalizar o exercicio da atividade política em geral, com perdas e danos irreparáveis para os principais partidos e lideranças da Nova República.

Além disso, assistiram passivos - e frequentemente como cúmplices - ao crescimento de forças conservadoras - representadas pelas bancadas BBB (boi, bala e biblia), com as quais efetuavam "tenebrosas transações". Em troca de votos no Parlamento, entregavam postos ministeriais e posições de poder, além de favores, como, por exemplo, concessões de meios de comunicação. Em nome da chamada "governabilidade", instauraram o desgoverno, distanciando-se de seus compromissos e promessas originais.

Formou-se, assim, em uma atmosfera de exasperação de contradições, condições favoráveis à emergência de lideranças "salvacionistas", outsiders, supostos ou reais. ${ }^{16}$ Entretanto, ainda havia margens para deter a ascensão do bolsonarismo.

De fato, foi na curta duração, na campanha eleitoral de 2018, que se evidenciaram circunstâncias e que se tomaram decisões que determinariam a vitória do candidato da extremadireita. Ora, as interpretações que enfatizam unilateralmente as tradições autoritárias podem levar à subestimação ou à desconsideração dessa dimensão. Quando isso acontece, como já se disse, a política é expulsa da história.

\subsection{A campanha eleitoral de 2018 - a curta duração}

Na campanha eleitoral, território por excelência da política - na curta duração - tomaram forma especíica as contradições já analisadas na longa e na média duração. É preciso insistir, entretanto, de que, quando se abriram as manobras eleitorais, nada ainda estava decidido.

Que circunstâncias e opções conduziram à vitória de Bolsonaro?

De um lado, a subestimação de sua força e do potencial de seu crescimento. Prevaleceu a ideia de que, mais uma vez, haveria a polarização entre tucanos e petistas. Equívoco de consequências funestas. De outro lado, e como consequência, subestimou-se a necessidade de constituir, desde o primeiro turno, a mais ampla frente possivel das tendências de esquerda. De preferência em torno de um nome não vinculado ao PT, dada a rejeição alta do petismo. ${ }^{17} \mathrm{Nada}$ se fez nesse sentido. Ao contrário, a orientação foi no sentido de hostilizar e sabotar a candidatura Ciro Gomes, vista pelo petismo como rival ameaçador.

Um outro movimento suicida foi a insistência na candidatura Lula, mesmo se sabendo que, mesmo o lider libertado, ela era juridicamente inviável (Lei da Ficha Limpa). Quando, por fim, isso foi reconhecido (tarde demais?), e Fernando Haddad projetou-se como candidato, a campanha desse, ao longo do primeiro turno, reduziu sua pessoa - e sua imagem - a um "peão" de Lula, como se fora uma mera extensão do líder do PT, sem nenhum grau de autonomia. Esse erro foi corrigido no

\footnotetext{
15 A expressão foi usada pelo ex-governador da Bahia, Jacques Wagner, do PT, introduzindo jocosamente uma autocritica que jamais adquiriu profundidade.

16 Como se sabe, esta é igualmente uma tradição nacional. Que se recorde a ascensão de Jânio Quadros e de Fernando Collor, vencedores das eleições de 1960 e 1989, ambos se apresentando como candidatos "alternativos" a um sistema repudiado por amplas maiorias. 17 Nas últimas eleições argentinas, o mesmo não ocorreu: Cristina Kirchner, muito lucidamente, preferiu ocupar uma segunda posição em relação a Alberto Fernandez, um peronista moderado. Não apenas contornou a rejeição alta a seu nome como conseguiu unir diversas correntes peronistas em torno da chapa que, afinal, ganhou as eleições.
} 
segundo turno, contribuindo para melhorar as chances de Haddad. Tarde demais, porém, para reverter a onda favorável ao adversário.

Cumpre ainda destacar, no inventário de "cicatrizes" da campanha do derrotado, o fato de que ele foi muito discreto em relação a duas demandas básicas das amplas maiorias: a questão da segurança e a questão da corrupção. Incapaz de formular autocriticas a respeito de erros cometidos, entregou de bandeja ao adversário a exploração de temas que adquiriram grande apelo popular.

Ao mesmo tempo, e na medida em que a candidatura Geraldo Alckmin não decolava, Bolsonaro passou a ser o desaguadouro do voto antipetista, aumentando suas chances.

Outras circunstâncias ajudaram também a vitória do candidato da extrema-direita. Afinal, uma vitória não se resume à caracterização apenas dos erros do adversário.

Bolsonaro soube tecer importantes alianças com o capital financeiro (Paulo Guedes), apareceu como campeão da moralidade e da segurança (Moro), teceu e consolidou laços com as igrejas evangélicas (reação à pauta identitária dos costumes) e com outras forças conservadoras - as bancadas da "bala" (aparelhos de segurança e oficiais militares) e do boi (agronegócio de exportação). Em contraste com o que faziam Lula e o petismo, ampliou consideravelmente suas alianças, tornando-se estuário de uma ampla frente conservadora, bastante heterogênea, e que ia muito além das fronteiras estreitas da extrema-direita, da qual Bolsonaro sempre foi expressiva liderança.

E, ainda, houve o episódio do atentado, permitindo uma autoapresentação vitimizada, sempre simpática e sedutora, e - mais importante - legitimando a ausência nos debates políticos. ${ }^{18}$

$\mathrm{Na}$ etapa final do primeiro turno e ao longo do segundo turno, as pesquisas já davam Bolsonaro na frente. Os resultados finais confirmaram a vitória surpreendente de um candidato considerado até agosto de 2018 como um inevitável perdedor.

\section{0 caráter do Bolsonarismo}

A vitória de Bolsonaro, além de suscitar uma onda de sinistros e, no campo das tendências de esquerda, ensejou e tem ensejado remissões à conjuntura dos anos 1960 - que propiciou o golpe de 1964 - e/ou ao fascismo.

O país estaria no limiar de uma nova ditadura? Ou do ressurgimento do fascismo?

Em épocas de crise, quando as dúvidas se acumulam, é sempre tentador "explicar" o futuro pelo recurso ao passado. Às vezes, até atores sociais e políticos relevantes revestemse de atitudes e frases do passado, tentando reencarná-lo. Ressurge, então, a história como "magistra vitae". 19 É perder de vista que a história é a disciplina que estuda a mudança e que vida é mudança - e mudança permanente.

A conjuntura dos anos 1960 aconteceu há meio século. O mundo e o País mudaram muito nestes cinquenta anos para imaginar que seja possivel repetir o passado. Em relação ao fascismo, pela associação do mesmo exclusivamente à violência, tende-se a perder de vista suas especificidades históricas. ${ }^{20}$

Para a compreensão da ascensão da extrema-direita ao governo, um caminho mais fecundo talvez seja analisar suas alianças e caracteristicas especificas.

Convém enfatizar, uma vez mais, o contexto internacional. O bolsonarismo é a expressão brasileira de um movimento de reação internacional às mutações promovidas pela grande revolução digital ou informática.

Em uma análise especifica da força política do bolsonarismo, cumpre destacar, em primeiro lugar, seu núcleo mais coeso nos aparelhos de segurança formais (forças armadas e polícias) e informais (milícias e bancada da bala). Agrupam-se em torno dos conceitos de Ordem, de Segurança e de defesa da Pátria. Ignorados ou marginalizados ao longo dos anos da "Nova República", mastigaram ressentimentos represados que escoam agora com vigor. Antes

\footnotetext{
${ }_{18}$ Bolsonaro teve péssima participação nos dois debates anteriores ao atentado. Sua apresentação nos seguintes não era de bom agouro. A facada "salvou-o" de encontros com candidatos rivais até o fim da campanha.

19 A história como professora da vida. Expressão atribuída a Marco Túlio Cícero, pensador romano.

20 Cf. nota 7 supra.
} 
de 2018, Bolsonaro e seus filhos construíram seu prestígio apoiando sem reservas os interesses corporativos desses segmentos.

Em um segundo círculo estão as igrejas evangélicas, aglutinadas em torno de pautas conservadoras relativas aos costumes e com importante expressão parlamentar (bancada da bíblia). ${ }^{21}$ Cultivam notória aversão às demandas das lutas identitárias e ao consumo das drogas. Constituiram relevante base de apoio a Bolsonaro nas eleições, mas sua fidelidade não é absoluta ou monolítica, nem ganha definitivamente. Além disso, evidenciam discrepâncias com algumas expressões mais extremadas e violentas das propostas "securitárias" (bandido bom é bandido morto). Tudo indica que desempenharão papel importante na legalização do novo partido que Bolsonaro quer dirigir, a Aliança para o Brasil. Neste caso, haverá um processo de mão dupla, negociado, pois as lideranças evangélicas, embora reacionárias, não estarão dispostas a serem meros reboques de propostas que não controlam.

Em um terceiro círculo, Bolsonaro conseguiu ampliar suas alianças para o "andar de cima", articulando apoios junto ao agronegócio (que não se confunde com o desmatamento desenfreado da Amazônia) e ao capital financeiro (o ultraliberalismo de Paulo Guedes). Essas manobras foram vistas, no início, como mero oportunismo eleitoral. Em um momento seguinte, no entanto, considerando o raquitismo eleitoral de Geraldo Alckmin e sua inviabilidade face ao petismo, esses setores migraram em peso para a candidatura Bolsonaro, poupando-o de críticas, relativizando suas invectivas, protegendo-o de denúncias. Imaginavam domesticá-lo, como fizeram com Lula, mas encontram dificuldades imprevistas para alcançar este objetivo.

Como se pode constatar, trata-se de uma aliança instável, pois mistura ingredientes muito heterogêneos que podem se desagregar com rapidez, dependendo das circunstâncias e dos rumos que tomar o governo.

Acresce uma particularidade, comum, aliás, às tendências do nacionalismo de ultradireita no mundo: o uso intensivo e agressivo/ofensivo dos meios digitais. Bolsonaro, seus aliados e correligionários investem furiosamente contra os adversários reais ou supostos, desrespeitam deliberadamente regras elementares de convivência (o "politicamente correto"), agridem amigos e inimigos, precipitam intrigas e discórdias, desafiam com arrogância o sendo comum e até mesmo verdades científicas estabelecidas (terraplanismo), criando "fatos novos" permanentes (ouviu a última do Bolsonaro?), em uma visada típica de quem deseja "épater les bourgeois" (escandalizar os burgueses). O objetivo, em grande parte alcançado, pelo menos até o momento, é o de "pautar o debate", manter a iniciativa a todo o custo. O procedimento, porém, suscita desgastes e defecções. Essa espécie de "motocontínuo", caso se associe a insucessos em outras áreas, pode gerar um crescimento inesperado de contradições e de oposições, criando dificuldades para Bolsonaro e o bolsonarismo.

Seja como for, não é de se imaginar que o bolsonarismo vá ser um fenômeno passageiro ou acidental. Trata-se de uma força política e social relevante. E permanente. E mais: em caso de fracasso, já tem um discurso pronto - "não nos deixaram governar". E, certamente, o que é mais sombrio, não se conformará em ser apeado do governo por métodos pacíficos e democráticos. Reagirá usando a força. De que modo e com que procedimentos concretos, o tempo dirá.

\section{Considerações finais}

É por isto mesmo que cumpre às oposições, em particular às esquerdas, se rearticularem e incentivarem à resistência. Seja através do protesto (nenhuma ação ou decisão arbitrárias do Governo pode passar em branco), seja por meio da resistência (impedir, quando for

\footnotetext{
${ }_{21}$ Observe-se que as igrejas evangélicas não constituem um todo monolítico. Entre elas, destacam-se algumas lideranças que estão no campo das esquerdas. Por outro lado, o voto evangélico pode evoluir segundo as conjunturas, não sendo os fiéis meros "carneiros" nas mãos de seus "pastores". Cf. Benjamin Arthur Cowan (2014). Tem crescido a literatura a respeito dos evangélicos, na proporção da importância dos mesmos na sociedade e na politica do país. Cf., entre outros, citados pelo autor referido: Saulo Baptista (2009) e Magali do Nascimento Cunha (2007)
} 
possivel, a concretização de medidas ou políticas governamentais) ou ainda, e melhor, por intermédio de elaboração de propostas alternativas. ${ }^{22}$

O problema é que os instrumentos partidários e sindicais tradicionais parecem muito mais envolvidos na própria sobrevivência e reprodução eleitoral do que interessados em suscitar lutas sociais e políticas. Destaque aí merece, infelizmente, o PT, maior partido das esquerdas, e que parece paralisado desde a vitória de Bolsonaro, incapaz de formular a indispensável autocrítica, embora defendida por algumas lideranças e setores da militância.

Assim, no limite, caberá à cidadania construir instrumentos de debate e de luta próprios, autônomos. Se não o fizer, ficará à mercê de acontecimentos e da orientação de forças que escapam largamente ao seu controle, como o bolsonarismo.

\section{Referências}

AARÃO REIS, Daniel. Ascensão e caráter do bolsonarismo. Novembro, 2019.

AARÃO REIS, Daniel. As armadilhas da memória e a reconstrução democrática. In: ABRANCHES, Sergio et al. Democracia em Risco? 22 ensaios sobre o Brasil de hoje. São Paulo: Companhia das Letras, 2019a. p. 274-286.

AARÃO REIS, Daniel. Aproximações, contrastes e contradições entre paradigmas de mudança social: os cinquenta anos de 1968. In: AARÃO REIS, Daniel et al. 1968, reflexos e reflexões. São Paulo: Edições SESC, 2018. p. 15-30. https://doi.org/10.29146/eco-pos.v21i1.18479.

AARÃO REIS, Daniel; RIDENTI, M.; MOTTA, Rodrigo Patto Sá (org.). A ditadura que mudou o Brasil. Rio de Janeiro: Jorge Zahar, 2014. https://doi.org/10.22228/rt-f.v8i2.442.

ALONSO, Angela. A comunidade moral bolsonarista. In: ABRANCHES, Sérgio et al. Democracia em Risco? 22 ensaios sobre o Brasil de hoje. São Paulo: Companhia das Letras, 2019. p. 52-70.

ASH, Timothy Garton. Os fatos são subversivos. Escritos politicos de uma década sem nome. São Paulo: Companhia das Letras, 2011.

ABRANCHES, Sergio et al. Democracia em Risco? 22 ensaios sobre o Brasil de hoje. São Paulo: Companhia das Letras, 2019.

BAPTISTA, Saulo. Pentecostais e Neopentecostais na politica brasileira: um estudo sobre a cultura política, estado e atores coletivos religiosos no Brasil. São Paulo: Annablume, 2009. https://doi. org/10.5752/1219.
CORDEIRO, Janaina Martins. A ditadura em tempos de milagre: comemorações, orgulho e consentimento. Rio de Janeiro: FGV, 2015.

COWAN, Benjamin Arthur. "Nosso terreno": crise moral, política evangélica e a formação da "Nova Direita" brasileira. Vária História, Belo Horizonte, v. 30, n. 52, p. 101-125, jan./abr. 2014. https://doi.org/10.1590/ s0104-87752014000100006.

CUNHA, Magali do Nascimento. A explosão gospel: um olhar das ciências humanas sobre o cenário evangélico no Brasil. Rio de Janeiro: Mauad, 2007. https:// doi.org/10.11606/t.27.2004.tde-29062007-153429.

FELICE, Renzo de. Interpretations of fascism. Cambridge: Harvard University Press, 1977.

FERREIRA, Gustavo Alves Alonso. Cowboys do asfalto. Rio de Janeiro: Record, 2015.

FRASER, Nancy. Mapeando a imaginação feminista: da redistribuição ao reconhecimento e à representação. Estudos Feministas, Florianópolis, v. 15, n. 2 , maio/ago., p. 291-307, 2007. https://doi.org/10.1590/ s0104-026×2007000200002.

FROMM, Erich. Escape from freedom. Nova York: Holt, Rinehart and Winston, 1941.

GENTILE, Emilio. La via italiana al totalitarismo. Partido y Estado en el régimen fascista. Buenos Aires: Siglo Veinteuno Editores, 2005.

GINSBURG, Tom; HUQ, Aziz Z. How to lose a constitutional democracy? UCLA Law Review, [S. L.], v. 65, n. 1. p. 78-169, 2018.

GOMES, Paulo César. Liberdade vigiada: as relações entre a ditadura militar brasileira e o governo francês: do golpe à anistia. Rio de Janeiro: Record, 2019. v. 1. 560 p.

GRINBERG, Lucia. Partido politico ou bode expiatório: um estudo sobre a Aliança Renovadora Nacional/ARENA, 1965-1979. Rio de Janeiro: Mauad/ FAPERJ, 2009. https://doi.org/10.26512/emtempos. Voi17.19906.

LANDAU, David. Abusive Constitutionalism. University of California at Davis Law Review, [S. L.], v. 47, p. 189260, 2013.

LEVITSKY, Steven; ZIBLATT, Daniel. Como as democracias morrem. Rio de Janeiro: Zahar, 2018.

LINZ, Juan J. Totalitarian and Authoritarian Regimes. Boulder: Lynne Rienner, 2000.

LINZ, Juan; ALFRED, Stepan (ed.). The breakdown of democratic regimes: Europe. Baltimore: Hopkins University Press, 1978

MAGALHÃES, Livia Gonçalves. Com a taça nas mãos: sociedade, copa do mundo e ditadura no Brasil e na Argentina. Rio de Janeiro: Lamparina/Faperj, 2014.

22 Cf. os ensaios estimulantes de Slavov Zizek (2019). Embora nem sempre concordando com suas análises, suas propostas de enfrentamento do "populismo de direita" são sempre encorajadoras. Cf., em particular o capítulo 6 do livro citado (2019, p. 273-349). 
MAIA, Tatyana de Amaral. Cardeais da cultura nacional: o Conselho Federal de Cultura na ditadura civil-militar (1967-1975). 1. ed. São Paulo: Instituto Itaú Cultural; Iluminuras, 2012. v. 1. 236 p.

MOTTA, Rodrigo Patto Sá. As Universidades e o Regime Militar: cultura política brasileira e modernização autoritária, Rio de Janeiro: J. Zahar. No prelo, 2014a.

PAXTON, Robert O. A anatomia do fascismo. São Paulo: Paz e Terra, 2007.

PINTO, Antonio Costa. O corporativismo nas ditaduras da época do fascismo. Vária História, Belo Horizonte, n. 52, v. 30, p. 17-49, jan./abr. 2014. https:// doi.org/10.1590/s0104-87752014000100002.

ROLLEMBERG, Denise. Memória, opinião e cultura política: a Ordem dos Advogados do Brasil sob a ditadura, 1964-1974. In: AARÃO REIS, Daniel; ROLLAND, Denis (org.). Modernidades Alternativas. Rio de Janeiro: FGV, 2008. p. 57-96.

ROLLEMBERG, Denise. A Associação Brasileira de Imprensa/ABI e a ditadura, 1964/1974. In: ROLLEMBERG, Denise; QUADRAT, Samantha Viz (org.). A construção social dos regimes autoritários: legitimidade, consenso e consentimento no século XX, v. 2, Brasil e América Latina. Rio de Janeiro: Civilização Brasileira, 2010. p. 97-144.

ROLLEMBERG, Denise; QUADRAT, Samantha Viz (org.). A construção social dos regimes autoritários: legitimidade, consenso e consentimento no século XX, 3 volumes. Rio de Janeiro: Civilização Brasileira, 2010a.

RUNCIMAN, David. Como a democracia chega ao fim. São Paulo: Todavia, 2018.

SCHWARCZ, Lilia Moritz. Sobre o autoritarismo brasileiro. São Paulo: Companhia das Letras, 2019.

SOLANO, Esther. A bolsonarização do Brasil. In: ABRANCHES, Sergio et al. Democracia em Risco? 22 ensaios sobre o Brasil de hoje. São Paulo: Companhia das Letras, 2019. p. 307-321.

STARLING, Heloisa Murgel. O passado que não passou. In: ABRANCHES, Sergio et al. Democracia em Risco? 22 ensaios sobre o Brasil de hoje. São Paulo: Companhia das Letras, 2019. p. 337-354.

STERNHELL, Zeev; SZNADER, Mario; ASHERI, Maia. The origins of fascist ideology. Princeton: Princeton University Press, 1994. https://doi.org/10.1017/ s0034670500019835.

STRAUSS, David. Law and the slow-motion emergency. In: SUNSTEIN, Cass R. (ed.). Can it happen here? New York: Harper Collins, 2018. p. 365-386.

TORNEY, Simon. Populismo: uma breve introdução. São Paulo: Cultrix, 2019.

PRZEWORSKI, Adam. Crises of democracy. Cambridge: Cambridge University Press, 2019.

ZIZEK, Slavoj. A coragem da desesperança. Rio de Janeiro: Zahar, 2017

\section{Endereço para correspondência}

Daniel Aarão Reis

Universidade Federal Fluminense

Rua Marcos Waldemar de Freitas Reis, s/n, bloco O, sala 505

Campus do Gragoatá, 24210-201

Niterói, RJ, Brasil 